DANIEL ROURKE is currently undertaking a practice based $\mathrm{PhD}$ in Art at Goldsmiths. His research explores human error and the digital through the ontology of writing.

Email: d.rourke@gold.ac.uk

\title{
Short Circuits
}

\section{The Doctrine of the Similar (GIF GIF GIF)}

\author{
Daniel Rourke
}

\begin{abstract}
IMPORTANT NOTE FROM EDITOR AND AUTHOR
This paper contains many animated GIF images. They have been left paralysed

by their conversion to PDF format. You can, however, view them on the author's website

http://machinemachine.net/text/ideas/the-doctrine-of-the-similar-gif-gif-gif
\end{abstract}

IN TWO SHORT ESSAYS written in 1933, Walter Benjamin argued that primitive language emerged in magical correspondence with the world. ${ }^{1}$ The faculty we all exhibit in childhood play, to impersonate and imitate people and things loses its determining power as language gradually takes over from our 'non-sensuous' connection with reality. In a break from Saussurean linguistics, Benjamin decries the loss of this 'mimetic faculty', as it becomes further replaced by the 'archive of non-sensuous correspondences' we know as writing.

To put it in simpler terms ... where once we read the world, the stars or the entrails of a sacrificed animal, now we read the signs enabled and captured by written language. From Benjamin, The Doctrine of the Similar: 
So speed, the swiftness in reading or writing which can scarcely be separated from this process, would then become ... the effort or gift of letting the mind participate in that measure of time in which similarities flash up fleetingly out of the stream of things only in order to become immediately engulfed again. ${ }^{2}$

The GIF - standing for Graphical Interchange Format - has been around since 1987. Their early popularity was based, in part, on their ability to load in time with a web page. In the days of poor bandwidth and dial-up connections this meant that at least part of a GIF image would appear before the user's connection broke, or - more significantly - the user could see enough of the image for it to make sense. In the mid-90s, avid web hackers managed to crack the code of GIFs and use this 'partial loading' mechanism to encode animations within a single GIF file. Thus the era of personal web pages saturated with looping animations of spinning hamsters was born.

Brought on (ironically) by their obsolescence the GIF has become the medium of choice for web artists, propagating their particular net-aesthetic through this free, open and kitschy medium. GIFs inhabit the space between convenience and abundance, where an apparent breakdown in communication can stimulate new modes of expressing non-sensuous similarities in the internet world.

Sites like dump.fm, 4chan and ytmnd revel in the GIF's ability to quickly correspond to the world. GIFs can be broken into their constituent frames, compressed and corrupted on purpose and made to act as archives for viral events travelling the web. A playground of correspondences that at first reflected language and the wider world now looks increasingly inward. Finding meaning in the semiotic sludge of these GIFs requires a sensitivity to similitude bordering on the magical.

GIFs take a variety of forms, some of which I will try to classify here:

GIF Type I: Classic
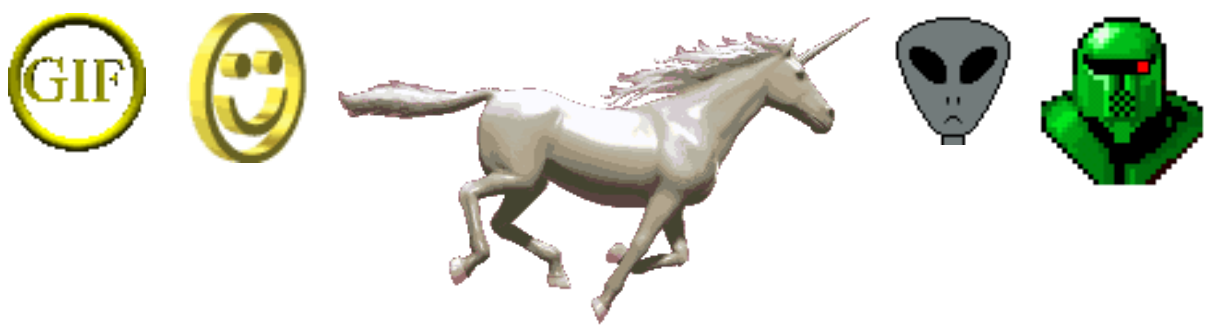

Small in size and made up of few frames, this is where animated GIFs began. Corresponding to single words or concepts such as 'smile', 'alien' or 'flying pink unicorn'.

GIF Type II: Frame Capture 

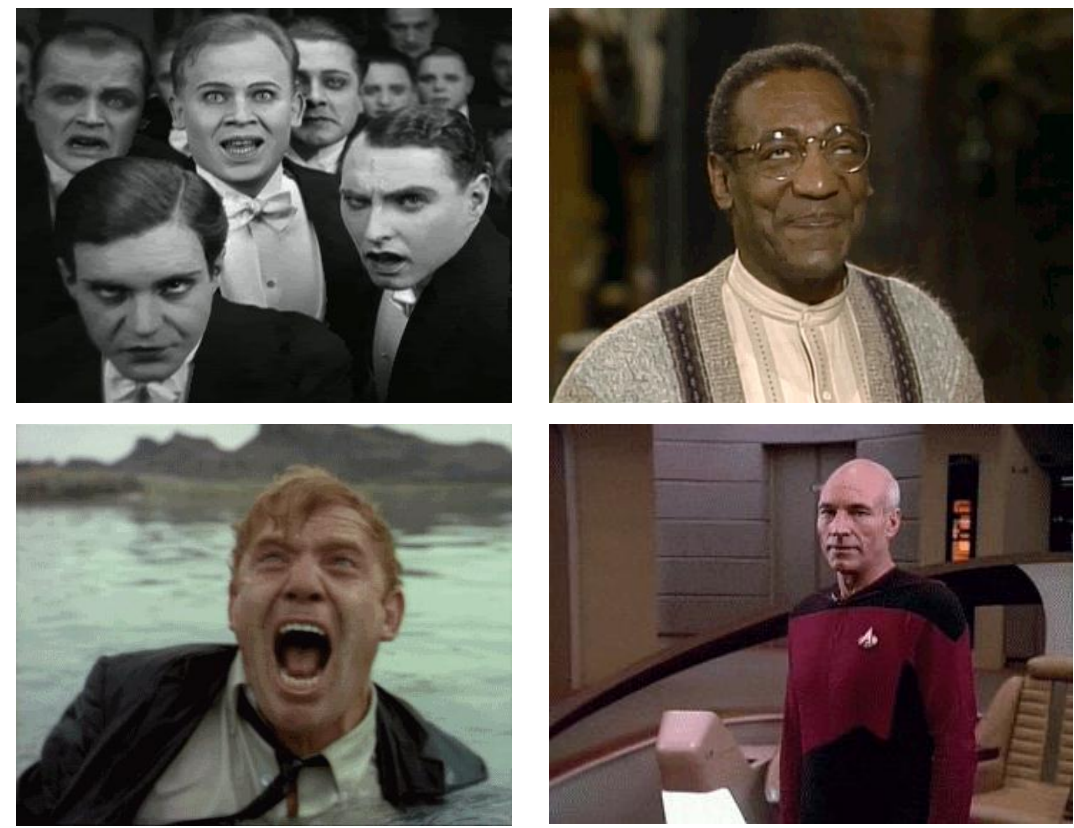

Frame grab or video-capture GIFs pay homage to well-known scenes in pop culture. But as the 'art' of animated GIFs grew the frame capture began to stand for something isolated from context. This leap is, for me, the first point at which GIFs begin to co-ordinate their own realm of correspondence. An ocean of viral videos turned into a self-serving visual language, looping back on itself ad infinitum.

\section{GIF Type III: Art}
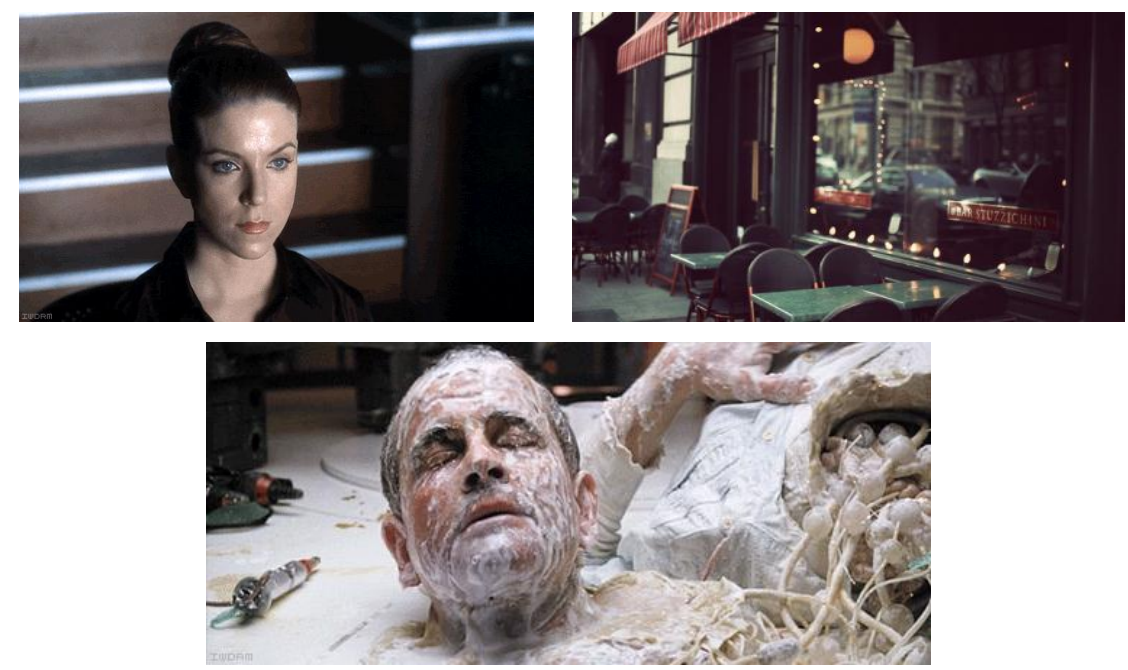

Leaking then directly into the third category, we have the Art GIF. Much larger in resolution and aware of their heritage in cinema, these GIFs are acutely refined in their choice of framing. 

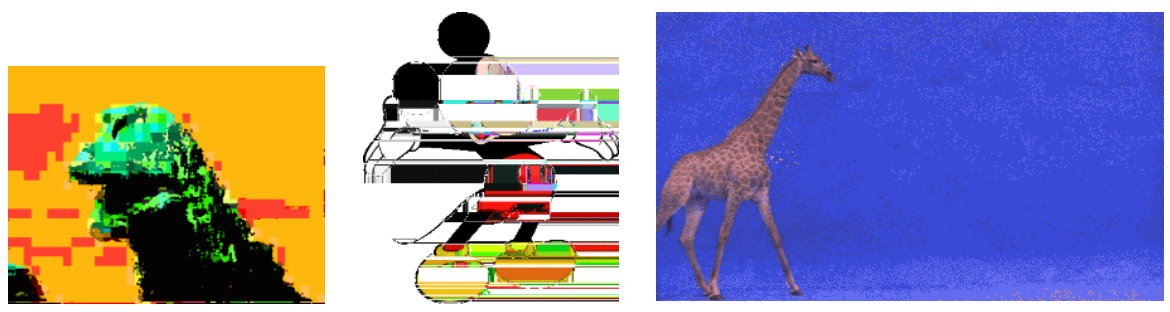

A badly encoded or compressed GIF can result in odd, strangely beautiful phenomena, and with a little skill and coding ability these glitches can be enhanced to enormous proportions. Glitch GIFs break the boundaries of another non-sensuous realm: that of computer code. A significant magical order Benjamin was little capable of predicting.

GIF Type V: Mash-Up
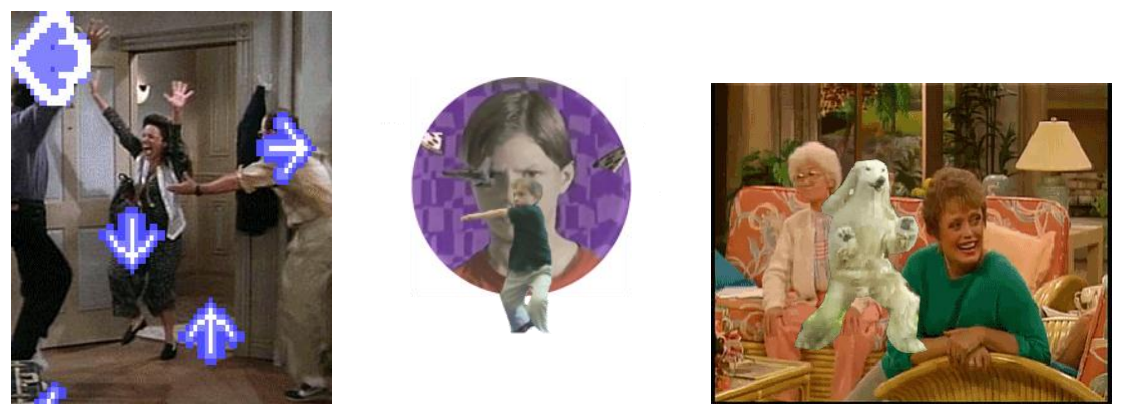

Lastly, and perhaps most prolific, is the mash-up GIF. These GIFs are composed of a combination of all the previous forms. The mash-up is the most innerlooking species of GIF. It is possible to track the cultural development of some of these. Often, though, the source of any original correspondence becomes completely lost in the play of images.

Other types

sci-tech/educational

geometric/texture

3D renders

$\underline{8 \text { bit inspired }}$

mise en abyme

Here again, I think Benjamin's essay can help us:

Language is the highest application of the mimetic faculty: a medium into which the earlier perceptive capabilities for recognising the similar had entered without residue, so that it is now language which 
represents the medium in which objects meet and enter into relationship with each other ... ${ }^{3}$

In other words, what these images mean I can't tell you in words. But perhaps by showing you other GIFs I might go some way to helping you understand them.

\section{Goldsmiths College, University of London}

GIFs sourced from: dump.fm: ryder, timb, ucnv / tumblr: iwdrm, maxcapacity, ace calhoun / web: ryder ripps

\section{Notes}

\footnotetext{
${ }^{1}$ Walter Benjamin, 'On the Mimetic Faculty', in Beyond the Body Proper: Reading the Anthropology of Material Life, eds. Margaret Lock and Judith Farquhar, (Duke University Press, 2007), pp. 130-132; and Walter Benjamin and Knut Tarnowski, 'The Doctrine of the Similar', New German Critique, 17, Special Walter Benjamin Issue (Spring 1979), Duke University Press, pp. 65-69. Accessed online at <http://www.jstor.org/stable/488010>

${ }_{2}^{2}$ Benjamin and Tarnowski (1979).

${ }^{3}$ Ibid.
} 